Article

\title{
Restrictions on the Use of Specimens Based on Magnesium and Titanium Nanocrystalline Oxides in Incidents Involving Uncontrolled Release of Hazardous Substances
}

\author{
Tomasz Węsierski *, Małgorzata Majder-Łopatka and Agata Walczak \\ Faculty of Safety Engineering and Civil Protection, The Main School of Fire Service, 52/54 Słowackiego Str., \\ 01-629 Warsaw, Poland; mmajder@wp.pl (M.M.-Ł.); awalczak@sgsp.edu.pl (A.W.) \\ * Correspondence: wesierskitomasz@poczta.onet.pl
}

Received: 12 November 2019; Accepted: 23 December 2019; Published: 30 December 2019

Featured Application: The results of the study could improve the practical use of sorbents and neutralizers during chemical rescue operations.

\begin{abstract}
Undertaking effective and prompt action during chemical events is an important measure in preventing the spread of contamination. Studies have shown that despite very high surface activity of nanocrystalline metal oxides, their use does not reduce the fire hazard for hydrocarbon spills and alcohols more effectively than commonly used sorbents during fire rescue operations. Other limitations of specimens containing nanocrystalline oxides have also been proven, such as the maximum absorption similar to commonly used specimens, as well as high costs of conducting the acid neutralization process without increasing the level of safety of operations. Results obtained allowed the determination of proposed principles of effective and economically appropriate application of nanocrystalline metal oxides in rescue units.
\end{abstract}

Keywords: rescue operation limitations; nanooxides; decontamination; fire hazard limitation

\section{Introduction}

In the case of chemical incidents a crucial safety requirement is to take appropriate action to prevent the spread of danger as soon as possible. This may be done, among other methods, by sealing, collecting, reducing the evaporation of backwaters and minimizing the amount of dangerous vapors that are already airborne. It should also be borne in mind that he hazard level is not only limited to the function of the physicochemical properties of the substance, but also of fluctuations in weather conditions [1,2]. Rescue units specifically designated for rescue and fire-fighting operations that involve hazardous substances represent a small percentage of all fire brigades. In a medium-sized European Union country with a well-developed fire protection system, such as Poland, specialized chemical rescue units constitute $1.3 \%$ of all rescue and fire-fighting units. Consequently the probability of such a unit being the first to arrive at the scene of an incident is relatively low. Consequently it is essential to ensure the best possible safety level and the capability of responding safely to units that normally do not perform chemical tasks and, as a result, could be the first to arrive on the scene.

Enabling units to respond effectively, without delay and maintaining the due safety is one of the important elements of the modern approach to chemical rescue problems. This suggests that it is advisable to seek measures that meet the above assumptions. It seems that measures that might prove to be universal could include oxide neutralizers with nano-scale crystallite sizes, especially technical solutions that enable the administration of these substances in a manner comparable to extinguishing 
powders [3]. This method of application is both handy and intuitive for rescuers and allows effective neutralization of chemical hazards on a very small scale. However, research carried out in the course of this article has shown quite clearly that this is not an ideal solution, but merely a complementary one.

\section{Neutralization Technologies Based on Nanocrystalline Metal Oxides}

Neutralization technology is not only limited to acid-base chemical neutralization, but also includes the elimination or minimizing of hazardous properties of a substance that undergoes uncontrolled release. Such a broad approach imposed the necessity of finding a universal solution that would concurrently be easy to use. The current neutralization technologies use decontamination solutions based on various types of oxidants (such as: hydrogen peroxide, ozone, chloramine, peracetic acid, salts of dichloroisocyanuric acid, persulphates, urea, percarbonates, magnesium perphthalate, etc.) [4-11]. However, this technology is not universal and it mainly comprises the removal of threats related to toxic compounds of organic origin.

In the most common neutralization technologies use is made of mixtures that consist of nanoparticles of such metal oxides as $\mathrm{MgO}, \mathrm{CaO}, \mathrm{ZnO}, \mathrm{SrO}, \mathrm{TiO}_{2}, \mathrm{Al}_{2} \mathrm{O}_{3}, \mathrm{CuO}, \mathrm{Fe}_{2} \mathrm{O}_{3}$ with grain diameters ranging from a few nanometers to several dozen micrometers [12-44]. The nanocrystalline $\mathrm{MgO}$ with grains of a $4 \mu \mathrm{m}$ diameter and a specific surface exceeding $500 \mathrm{~m}^{2} / \mathrm{g}$ is characterized by a particularly large surface and activity $[14-18,30,34]$. Reducing the size of nanocrystallites causes a significant increase in the share of surface atoms, including those occupying edge and corner places, particularly as their network defects comprise the active sites of the oxide neutralizer [34]. Consequently, the material that contains crystallites with a diameter of $2 \mu \mathrm{m}$ has more than half of the atoms/ions located on the surface and a specific surface close to $1000 \mathrm{~m}^{2} / \mathrm{g}$. It should be borne in mind that $10 \%$ of the locations are occupied by edge atoms/ions and $1 \%$ by corner ones [45].

An important feature of nanocrystallites is also the size of inter-crystalline pores. Given that their size is close to the size of the nanocrystals themselves, this significantly affects the diffusion characteristics of gases. At a diameter below $10 \mu \mathrm{m}$ the Knudsen diffusion area is entered where collisions between gas molecules occur less frequently than collisions between pore walls. This is the cause of a smaller mass transfer through the nanocrystalline material by three to four orders of magnitude and promotes the phenomenon of capillary condensation that allows the effective capture of air vapors.

Besides the typical acid-base neutralization, nanooxide-based specimens lead to dissociative adsorption on the surface of nanocrystals. As a consequence, in addition to chemisorption, the molecule breaks down into less toxic elements by hydrolysis of PO, P-CN, PS bonds [34,35,37], CX (X = F, Cl, Br, I) $[21,22,29]$. Such processes take place in a wide range of toxic industrial agents (TSP), halogenated organic warfare agents, as well as paralytic-convulsive (sarin, tabun, soman, VX), stinging (luisite, HD), asphyxiant $\left(\mathrm{COCl}_{2}\right)$, and general toxic ones $\left(\mathrm{AsH}_{3}, \mathrm{HCN}\right)$. The dissociative chemisorption process is known in literature for polar water molecules and alcohols on the surface of $\mathrm{MgO}(100)[42,46]$. Dissociative chemisorption does not occur on sorbents based on activated carbon [41].

As has been mentioned earlier, nanotechnologies based on oxide mixtures also have the ability of absorbing vapors of hazardous substances from the atmosphere. For the $\mathrm{MgO}-\mathrm{TiO}_{2}$ mixture, after $2 \mathrm{~min}$, a concentration reduction of over $95 \%$ is observed for such vapors and gases as $\mathrm{NH}_{3}, \mathrm{Cl}_{2}$, $\mathrm{CH}_{2} \mathrm{OCH}_{2}, \mathrm{HCl}, \mathrm{NO}_{2}, \mathrm{SO}_{2}, \mathrm{CH}_{3} \mathrm{SH}[3]$.

As regards toxic warfare agents, $\mathrm{MgO}, \mathrm{CaO}, \mathrm{SrO}, \mathrm{Al}_{2} \mathrm{O}_{3}$ and mixed $\mathrm{MgO}-\mathrm{Al}_{2} \mathrm{O}_{3}$ and $\mathrm{SrO}-\mathrm{Al}_{2} \mathrm{O}_{3}$ oxides are particularly active when prepared in the form of a modified airgel $[29,36,37,39]$. The studies have shown that a large absorbent surface limits the efficiency of the technology in conditions involving high humidity or the presence of water, which deactivates oxide specimens by adsorbing partially. The problem was solved by hydrophobizing the surface with a special carbon layer [40]. An additional protection against moisture absorption from the air and, at the same time, an element enhancing the convenience of using the technology, is the concept of placing neutralizers in pressure cylinders modeled on fire extinguishers. Thanks to its simplicity and intuitiveness, such a solution 
enables quick and effective use of the technology, especially during the most frequently occurring small and local events, and additionally during the final stage of liquidation of residues of hazardous chemical compounds.

Despite nanooxides offering a clearly wide range of advantages, literature does not provide information related to potential limitations of their usage during rescue actions, or comparative studies as to the most frequently used types of sorbents and neutralizers during uncontrolled releases of hazardous substances. Given the intense time pressure on the incident scene, actions undertaken by the rescuers entail great dynamics. The chosen materials have to be intuitive in use, easily accessible, harmless, allow achieving quick effects and must also be affordable. The present article attempts to find a solution for the scope of practical range of usage of sorbents and neutralizers used to date in relation to metal nanooxides, taking into consideration needs of the rescuers. Research methods presented in the article attempt to provide the best possible description of the rescuer's field of work emphasizing also his needs, which include among others collection/neutralization of the maximum amount of substance by a unit mass of sorbent/neutralizer, minimizing the fire risk and the toxicological hazard by reducing the evaporation rate of the substance or its chemical binding, limiting the risk of temperature-related effects of the neutralization process (risk of burns, splashing, and increased vaporization that limits the rescuer's visibility splay).

\section{Experimental Part}

\subsection{Materials}

In the studies use was made of Avantor Performance Materials reagents with a purity of min. $99.5 \%$.

\subsection{Research Methodology}

Comparative tests were carried out to determine the effectiveness of metal nanooxides based specimens. The studies used sorbents designated in this article as CDE, PC, EP and hydrophobized nanocrystalline oxide preparation ${\mathrm{MgO}-\mathrm{TiO}_{2}}_{2}$ (designated as FastAct $(\mathrm{FA})$, with bulk density d $=0.47 \mathrm{~g} / \mathrm{cm}^{3}$, grain diameter $\varphi<10 \mathrm{~nm}$.). The characteristics of the tested sorbents are presented in Table 1. CDE, PC, EP type sorbents are very popular sorbents commonly used by rescue entities in Europe [47,48].

Table 1. The characteristics of the tested sorbents.

\begin{tabular}{|c|c|c|}
\hline Designation & Trade Name & Characteristics \\
\hline $\mathrm{CDE}$ & Compakt & $\begin{array}{l}\mathrm{CDE} \text { is a granulated sorbent based on calcined diatomaceous } \\
\text { earth with } \mathrm{SiO}_{2} \text { composition }-75 \%, \mathrm{Al}_{2} \mathrm{O}_{3}-10 \%, \mathrm{Fe}_{2} \mathrm{O}_{3}-7 \% \text {, } \\
\mathrm{TiO}_{2}-1 \%, \mathrm{MgO}-2 \%, \mathrm{CaO}-1 \%, \mathrm{~K}_{2} \mathrm{O}+\mathrm{Na}_{2} \mathrm{O}-2 \% . \\
\text { bulk density } \mathrm{d}=0.53 \mathrm{~g} / \mathrm{cm}^{3}, \\
\text { grain diameter } 0.5<\varphi<1 \mathrm{~mm} .\end{array}$ \\
\hline PC & Unisafe & $\begin{array}{l}\text { PC is a sorbent whose active ingredient is polyacrylamide } \\
\text { copolymer. } \\
\text { bulk density } \mathrm{d}=0.37 \mathrm{~g} / \mathrm{cm}^{3} \\
\text { grain diameter } 0.05<\varphi<0.1 \mathrm{~mm} \text {. }\end{array}$ \\
\hline $\mathrm{EP}$ & Ekoperl66 & $\begin{array}{c}\text { EP is a silicate rock of volcanic approach (expanded perlite) } \\
\text { with the composition: } \mathrm{SiO} 2-74.9 \%, \mathrm{Al}_{2} \mathrm{O}_{3}-12.0 \% \text {, } \\
\mathrm{Fe}_{2} \mathrm{O}_{3}-0.8 \%, \mathrm{CaO}-0.6 \%, \mathrm{MgO}-0.1 \%, \mathrm{Na}_{2} \mathrm{O}-4.6 \% \text {, } \\
\mathrm{K}_{2} \mathrm{O}-4.7 \%, \mathrm{TiO}_{2}-0.4 \% \text {. Bulk density d }=0.078 \mathrm{~g} / \mathrm{cm}^{3} \text {, grain } \\
\text { diameter } 1<\varphi<3 \mathrm{~mm} .\end{array}$ \\
\hline FA & FastAct & $\begin{array}{l}\text { Hydrophobized nanocrystalline } \mathrm{MgO}-\mathrm{TiO}_{2} \\
\text { bulk density } \mathrm{d}=0.47 \mathrm{~g} / \mathrm{cm}^{3} \\
\text { grain diameter } \varphi<10 \mathrm{~nm}\end{array}$ \\
\hline
\end{tabular}




\subsubsection{Comparative Studies of Maximal Sorptivity}

The maximal sorptivity test was carried out using the Westinghouse method. The research stand is presented in Figure 1. An analytical sample of sorbent earlier subjected to sieving was placed in a conical stainless steel metal sieve with a diameter of $70 \mathrm{~cm}$ and $7.5 \mathrm{~cm}$ high. (mesh size $60 \mu \mathrm{m}$ ). Such a sample was then submersed in a sorbate solution. The sorbent was kept immersed in the sorbate until its complete moisturizing. Next the sample was taken out of the sorbate and hung on a tared scale, and the time measurement was started. Once the excess liquid had leaked away (after $10 \mathrm{~min}$ ), the mass of studied sorbents along with the sorbate was defined. The sorbate mass was calculated by subtracting the sieve and sorbent weight. By making a division by the mass of sorbent, the maximum sorbent mass sorptivity was obtained $S_{w}\left[\mathrm{~kg}^{-} 1 \mathrm{~kg}^{-1}\right]$. Due to the fact that the majority of chemical hazards are accidents involving petroleum derivatives, benzene was used as a representative substance for the hydrocarbons group.

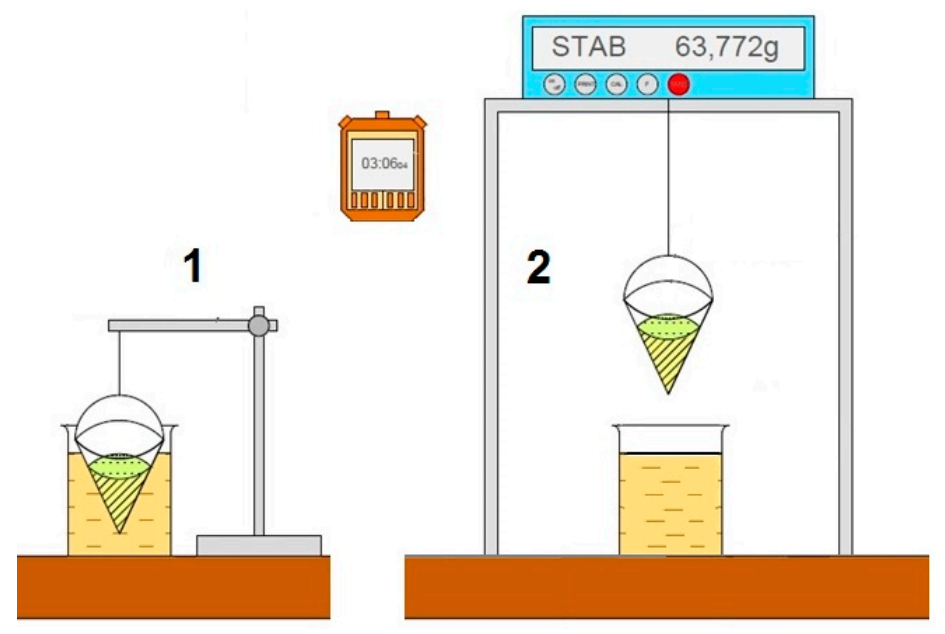

Figure 1. Scheme of test stages on the measurement stand: (1) immersion of analytical sorbent sample in the absorbed liquid, (2) dripping of absorbed liquid including control of sorbent-sorbate over time.

\subsubsection{Comparative Studies on the Evaporation Rate of Sorbate Adsorbed on Sorbent}

The evaporation rate for selected flammable substances, which in fact is also a measure of the fire hazard they pose, was determined by the weight loss resulting from evaporation of sorbate from an equal weight of sorbent from a $9 \mathrm{~cm}$ diameter plate. For the measurements, a balance with accuracy of mass reading $\Delta \mathrm{m}=0.001 \mathrm{~g}$ coupled with a time recorder with an accuracy of $0.2 \mathrm{~s}$ was used. The measurements were carried out in conditions without any limitations to the free evaporation process at the sorbent:sorbate 1:3 mass ratio. The measurement stand is shown on Figure 2. In the research $\mathrm{n}$-heptane and ethanol were used as representatives of compounds of substantially different chemical nature. Both compounds are also often the cause of uncontrolled releases in industry and transport and represent a wide group of industrially used hydrocarbons and alcohols. 


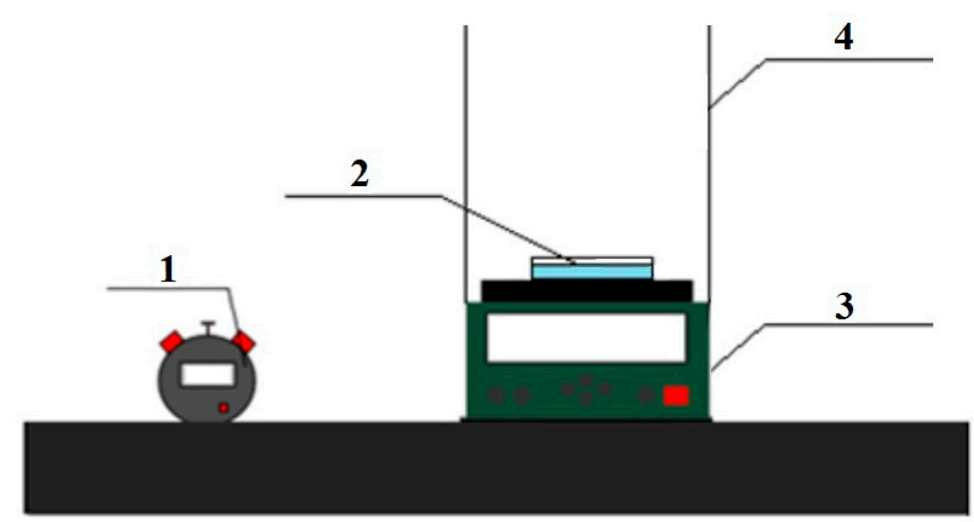

Figure 2. Diagram of a stand used to test the evaporation rate. (1) stopper, (2) tested substance set on Petri dish with a diameter of $9 \mathrm{~cm}$, (3) analytical scales, (4) side screen to reduce the impact of air movements.

\subsubsection{Comparative Tests of the Flash Point of Pure Substance and One Sorbed on the Sorbent}

The tests were carried out for p-xylene using the open crucible method according to Cleveland (Cleveland Open Cup) according to the Annual Book of ASTM (American Society for Testing and Materials) Vol 05.01 standards. Comparative tests for p-xylene sorbed on CDE and FA were carried out at the mass ratio of sorbate: sorbent 1:2, i.e., at a ratio much lower than the determined maximum absorption. The tests were carried out in relation to $\mathrm{p}$-xylene as that it is the measuring standard of this method and has very similar maximal absorption to benzene. CDE is the most commonly used sorbent by rescue units in Poland.

\subsection{4. $\mathrm{H}_{2} \mathrm{O}$ Absorption Rate and Aging of $\mathrm{MgO}-\mathrm{TiO}_{2}$ Specimens}

To test the rate of water vapor absorption, tests were carried out in a closed chamber with dimensions of $476 \mathrm{~mm} \times 676 \mathrm{~mm} \times 1002 \mathrm{~mm}\left(\mathrm{~V}=0.322 \mathrm{~m}^{3}\right) .10 \mathrm{~g}$ of FA and $150 \mathrm{~cm}^{3} \mathrm{H}_{2} \mathrm{O}(\mathrm{T}=293 \mathrm{~K})$ were placed in separate Petri dishes with diameters of $9 \mathrm{~cm}$ and $25 \mathrm{~cm}$, respectively, positioned $50 \mathrm{~cm}$ from each other. Sorption tests were started after the chamber reached a stable value of air humidity. Then changes in the mass of FA and hygroscopic representatives of neutralizing and extinguishing agents used in rescue operations were examined for a period of $180 \mathrm{~min}$. The measurement stand is shown on Figure 3.

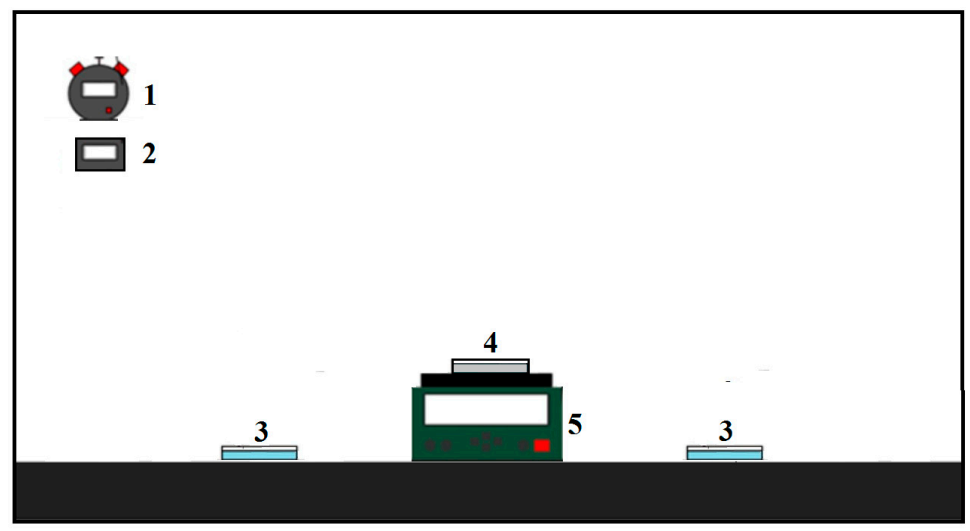

Figure 3. Diagram of stand used to test water sorption from the air. (1) Stopper, (2) hygrometer, (3) Petri dishes with evaporating water, (4) sorbent, (5) analytic scales. Closed chamber with dimensions of $476 \mathrm{~mm} \times 676 \mathrm{~mm} \times 1002 \mathrm{~mm}\left(\mathrm{~V}=0.322 \mathrm{~m}^{3}\right)$. 


\subsubsection{Comparative Studies of Efficiency and Safety of Acid Neutralization Process}

The quantitative efficiency of the acid neutralization process based on FA was tested by the traditional method, using for this purpose a $1 \mathrm{M}$ solution of $\mathrm{H}_{2} \mathrm{SO}_{4}$ as the reference acid. The determination was carried out in the presence of methyl orange. An examination was made of energy effects that accompany the neutralizing process of $98 \% \mathrm{H}_{2} \mathrm{SO}_{4}$ in simulated rescue and fire-fighting conditions on the assumption that the neutralization of spills using basic equipment at the initial stage will take place with a significant excess of $\mathrm{H}_{2} \mathrm{SO}_{4}$. The mass ratio of the neutralizer: $\mathrm{H}_{2} \mathrm{SO}_{4}$ of 1:10 (and comparatively 1:2) with mixing and without mixing of arrangement was used in experiments. The thermal effect was measured in a Dewar vessel ensuring stable temperature measurement and minimal heat exchange between the test system and the environment in relation to the effect. Such conditions would enable the determination of the maximum temperature effect without taking into account the heat exchange range between the spill and the spill surface. Studies of the nanocrystalline oxide specimen were related to the results obtained for commonly used neutralizers such as $\mathrm{NaOH}$, $\mathrm{Ca}(\mathrm{OH})_{2}, \mathrm{NaHCO}_{3}, \mathrm{Na}_{2} \mathrm{CO}_{3}$, and $\mathrm{CaO}$. The measurement stand is shown in Figure 4.

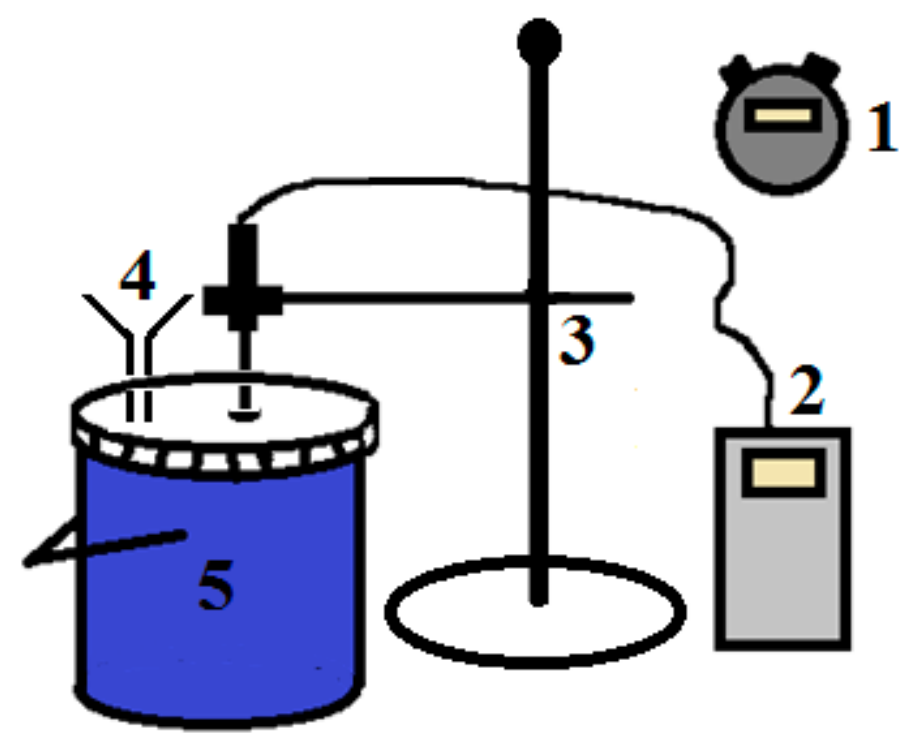

Figure 4. Diagram of stand used to test thermal effects of the neutralization process (1) Stopper, (2) electronic thermometer, (3) stand, (4) inlet, (5) Deware dish.

\section{Results and Discussion}

\subsection{Maximum Absorption}

Results of measurements of the maximum absorption in the Westinghouse method for benzene and selected sorbents have been presented in Table 2. By dividing the mass of sorbed benzene by the mass of used sorbent, the maximal mass sorptivity was obtained $S_{\mathrm{w}}\left[\mathrm{kg}^{-1} \mathrm{~kg}^{-1}\right]$. Taking into account the density of benzene and bulk density of sorbents, a calculation was made of the value of maximum volume of liquid that can be absorbed by a unit volume of sorbent (maximal volume sorptivity $\mathrm{S}_{\mathrm{v}}\left[\mathrm{dm}^{-3} / \mathrm{dm}^{-3}\right]$ ). It can be seen clearly that the nanocrystalline $\mathrm{MgO}-\mathrm{TiO}_{2}$ specimen (FA) does not exhibit higher maximal mass sorptivity $S_{W}$ or maximal volume sorptivity $S_{v}$ in relation to sorbents used so far during rescue operations. Much better $S_{w}$ results were obtained for expanded perlite (EP) and water-activated polyacrylamide copolymer (PC). In comparison to $\mathrm{MgO}-\mathrm{TiO} 2$, the $\mathrm{S}_{\mathrm{v}}$ parameter was better not only for water activated PC but also for calcinated diatomite earth sorbent (CDE). Considering also the significantly higher prices of nanooxides (min. $50 \mathrm{Euro} / \mathrm{kg}$ ), their use as sorbents of hydrocarbon substances seems to be highly unprofitable for the time being. The majority of sorbents currently used by fire services have a price well below 5 euro $/ \mathrm{kg}$. 
Table 2. Maximal sorptivity relative to benzene expressed in $[\mathrm{g} / \mathrm{g}]$ and $\left[\mathrm{dm}^{3} / \mathrm{dm}^{3}\right]$ for $\mathrm{MgO}-\mathrm{TiO}_{2}$ neutralizer (FA) and selected sorbents used in rescue operators during uncontrolled release of chemical substances (CDE, PC, EP).

\begin{tabular}{ccc}
\hline Sorbent & $\mathbf{S}_{\mathbf{w}}, \mathbf{k g}^{-\mathbf{1}} \mathbf{k g}^{-\mathbf{1}}$ & $\mathbf{S}_{\mathbf{v}}, \mathbf{d} \mathbf{m}^{-\mathbf{3}} \mathbf{d m}^{-\mathbf{3}}$ \\
\hline $\mathrm{CDE}$ & 1.11 & 0.52 \\
\hline PC (non-activated $\left.\mathrm{H}_{2} \mathrm{O}\right)$ & 1.15 & 0.37 \\
\hline PC (activated $\left.\mathrm{H}_{2} \mathrm{O}\right)$ & 2.40 & 0.78 \\
\hline EP & 4.58 & 0.31 \\
\hline FA & 1.10 & 0.45 \\
\hline
\end{tabular}

\subsection{Evaporation Rate of Sorbate Sorbed on Sorbent}

As regards physical sorption, it is necessary to monitor the evaporation of sorbate sorbed on sorbent. In order to verify the thesis and quantify the phenomenon, comparative samples of the tested specimens were prepared, on which n-heptane and ethanol had been sorbed. These compounds undergo physical sorption, while ethyl alcohol on the edge and corner atoms of $\mathrm{MgO}-\mathrm{TiO}_{2}$ nanocrystallites should also undergo chemical sorption to form $\mathrm{Mg}(\mathrm{OH})\left(\mathrm{OC}_{2} \mathrm{H}_{5}\right)$ [46]. It was noticed that at the mass ratio sorbent: sorbate 3:1 (which is far from maximal sorptivity), the weight loss of sorbate from FA is similar in magnitude and even greater than the weight loss recorded for evaporation from the surface of pure sorbate (Figures 5 and 6). This confirms the thesis of the decisive role played by physical sorption in the case of hydrocarbons and monohydric alcohols. However, increased evaporation could also result from the very large specific surface area. In both cases, CDE containing $0.5-1 \mathrm{~mm}$ grains turned out to be the sorbent releasing the least amount of vapors, which is due to the fact that the grains have a much less developed surface.

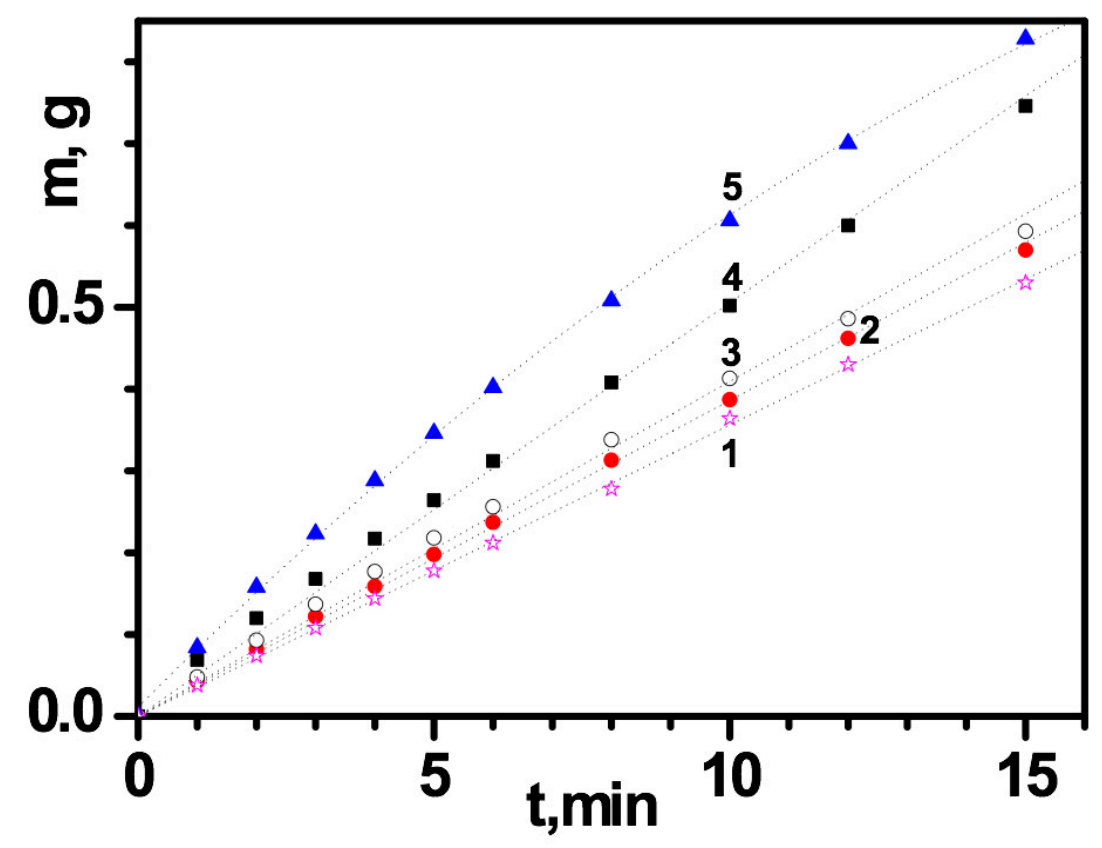

Figure 5. The weight loss of the sample as a function of time during free evaporation from the Petri dish with a diameter $d=9 \mathrm{~cm}$ for the system: (1) n-heptane-pure, (2) CDE:n-heptane, mass ratio 3:1, (3) FA:n-heptane, mass ratio 3:1, (4) PC:n-heptane, mass ratio 3:1, (5) EP:n-heptane, mass ratio 3:1. Temperature $\mathrm{T}=22{ }^{\circ} \mathrm{C}$, relative humidity $\mathrm{H}=25 \%$. 


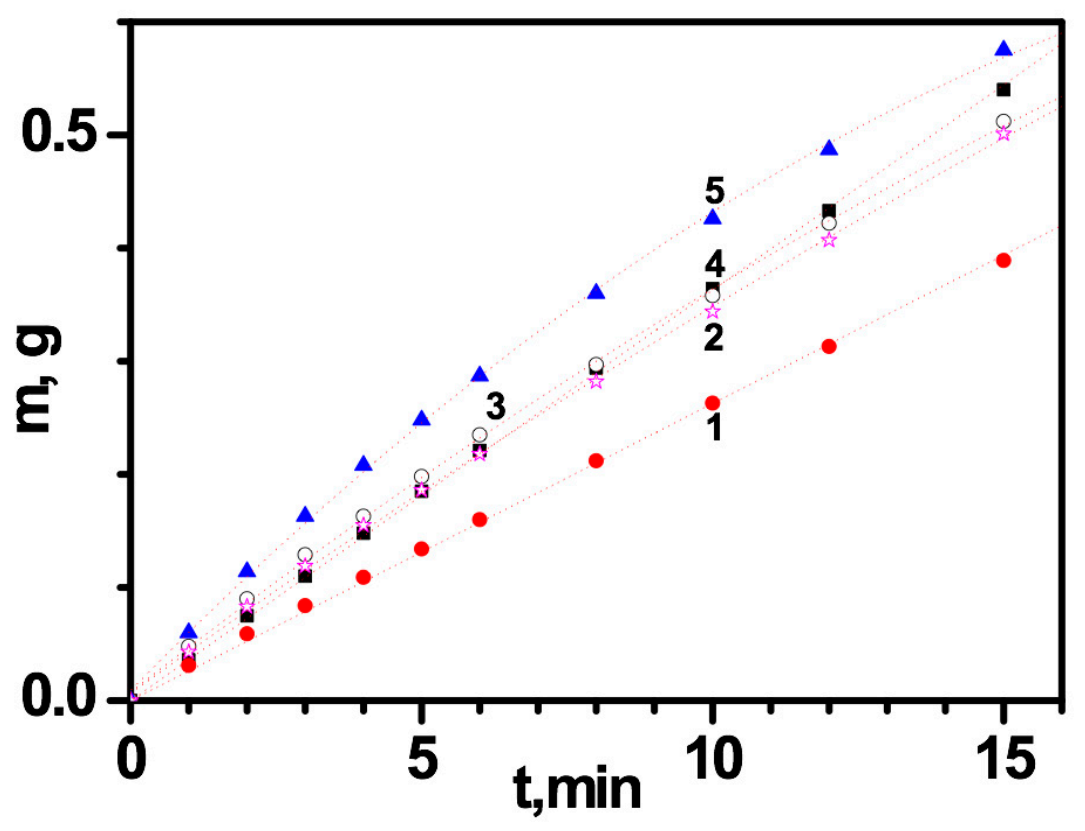

Figure 6. The weight loss of sample as function of time during free evaporation from the Petri dish with a diameter $\mathrm{d}=9 \mathrm{~cm}$ for the system: (1) CDE:ethanol, mass ratio 3:1, (2) ethanol-pure, (3) FA: ethanol, mass ratio 3:1, (4) PC: ethanol, mass ratio 3:1, (5) EP:ethanol, mass ratio 3:1. Temperature $\mathrm{T}=22{ }^{\circ} \mathrm{C}$, relative humidity $\mathrm{H}=25 \%$.

Studies of ethanol evaporation rate $\left(\mathrm{dmdt}^{-1} \cdot \mathrm{S}^{-1}\right)$ at different mass ratios sorbent:sorbate (configuration FA:ethanol) indicate that no mass loss occurs if ethanol content in the sample exceeds $5.58 \%$ (Figures 7 and 8 ). Below this ethanol concentration value the mass of arrangement starts to increase. This is due to the absorption of water vapor from the air by the FA.

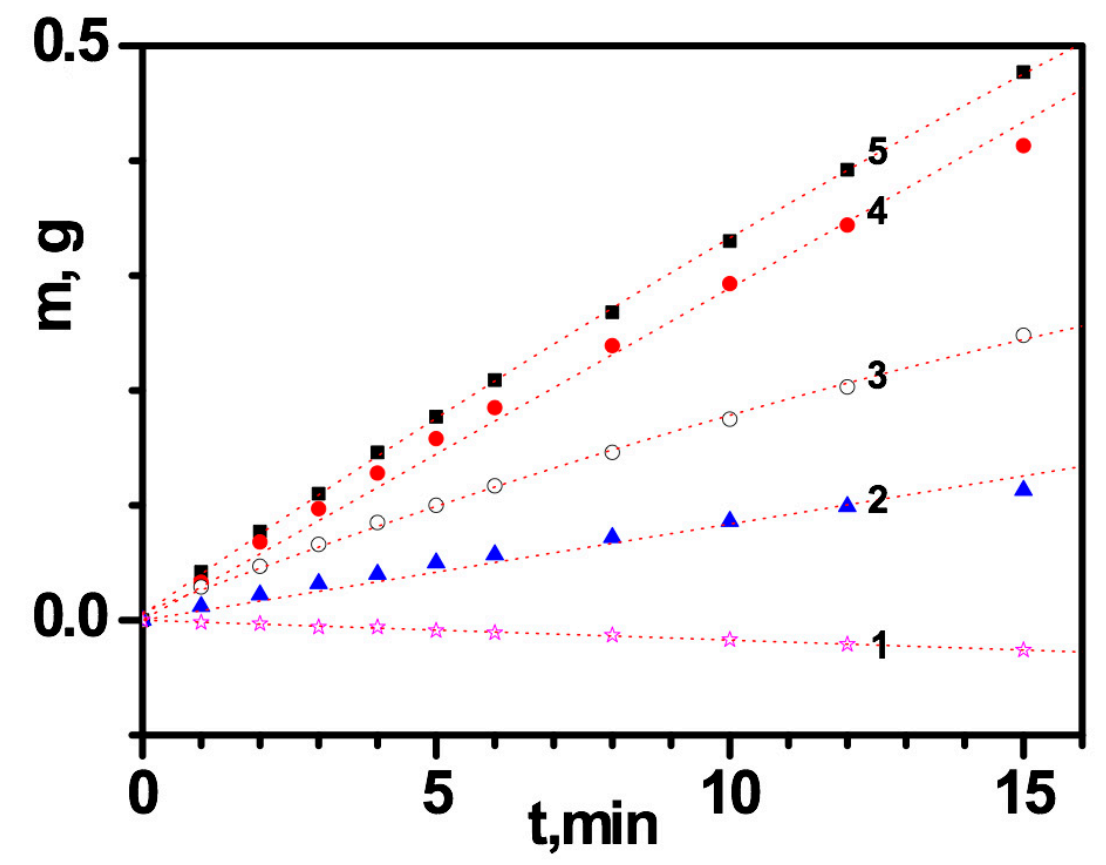

Figure 7. The loss weight of the sample as a function of time during free evaporation from the Petri dish with a diameter $d=9 \mathrm{~cm}$ for the system FA:ethanol with mass ratio: (1) 10:0.5, (2) 10:1, (3) 10:1.5, (4) 10:3, (5) 10:5. Temperature $\mathrm{T}=22{ }^{\circ} \mathrm{C}$, relative humidity $\mathrm{H}=25 \%$. 


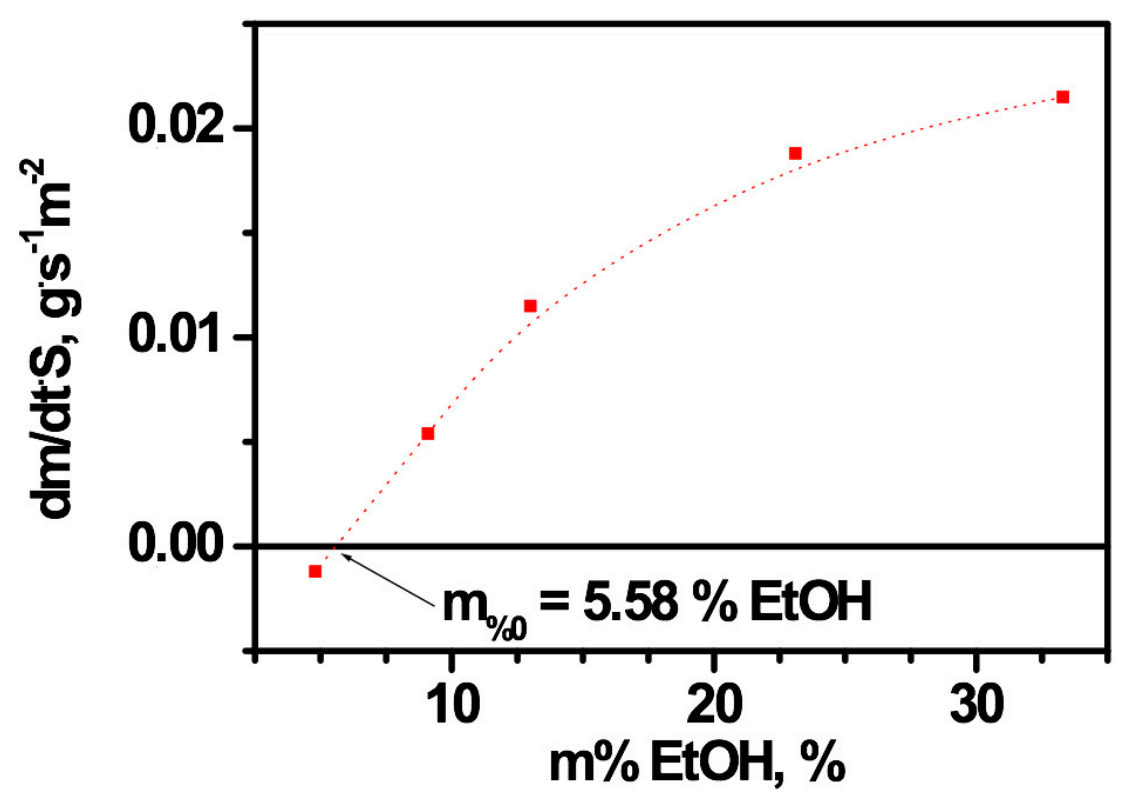

Figure 8. The rate of weight loss $\mathrm{dmdt}^{-1} \cdot \mathrm{S}^{-1}\left[\mathrm{~g} \mathrm{~s}^{-1} \mathrm{~m}^{-2}\right]$ for FA as a function of mass \% of ethanol in sample. Temperature $\mathrm{T}=22{ }^{\circ} \mathrm{C}$, relative humidity $\mathrm{H}=25 \%$.

Physical sorption means that comprise $\mathrm{MgO}-\mathrm{TiO}_{2}$ nanooxides do not allow achieving better results for the sorption of hydrocarbons and alcohols than sorbents used so far by rescue units. Considering the price of FA and its hygroscopicity, this limits its use during uncontrolled releases of this very numerous group of organic substances.

\subsection{Comparative Tests of the Flash Point of Pure Substance and One Sorbed on Sorbate}

The flash point of $99 \%$ purity of p-xylene determined by open Cleveland's cup method equaled to $34 \pm 2{ }^{\circ} \mathrm{C}$. The determined value proves to be consistent with literature data for this method. Adsorbing p-xylene at a sorbate:sorbent 1:2 mass ratio leads to a decrease in the flash point of vapor for both p-xylene absorbed by CDE and FA. This value is for configuration of $\mathrm{p}$-xylene: $\mathrm{CDE}$ and the p-xylene:FA configuration was $29 \pm 2{ }^{\circ} \mathrm{C}$ and $28 \pm 2{ }^{\circ} \mathrm{C}$ respectively. The study showed compliance with the results obtained for the evaporation rate measurements for $\mathrm{n}$-heptane and ethanol for which the evaporation rate from the sorbate: sorbent system is higher than from pure solvent already at a mass ratio of 1:3. This confirms that the FA increases the fire hazard immediately after absorption even more than standardly used in rescue operations CDE.

\section{4. $\mathrm{H}_{2} \mathrm{O}$ Absorption Rate and Aging of $\mathrm{MgO}-\mathrm{TiO}_{2}$ Specimens}

The use of technology in the form of neutralizing extinguishers requires that the nanocrystalline oxide preparation does not lump due to the tendency of water being absorbed from the air. Such a process could lead to clogging the extinguisher outlet consequently causing its uselessness.

These studies have shown that water vapors at $t=180$ min caused an average increase in mass of the FA at a rate of $\mathrm{dmdt}^{-1} \mathrm{~S}^{-1}=5.82 \times 10^{-1}\left[\mathrm{gmin}^{-1} \mathrm{~m}^{-2}\right]$. Despite the hydrophobization of FA, this result is more than twelve-fold greater than in the case of $\mathrm{CaO}$ and 37-fold greater than for hydrophobized $A B C$ powder with a monoammonium phosphate content of $90 \%$.

Despite such a high $\mathrm{dmdt}^{-1} \mathrm{~S}^{-1}$ value, no caking of FA was observed during the measurement. The product stored in the original and airtight plastic container has not been lumpy for over a year. Consequently it may be concluded that such an event should also not take place in a sealed neutralizing fire extinguisher in which FA is also commercially available. 


\subsection{Acid Neutralization}

Neutralization of typical acids using nanoactive oxide neutralizers is a very costly process. Such neutralizers currently available on the market cost over 50 euro $/ \mathrm{kg}$. For the sake of comparison, the cost of commercially available technical grade $\mathrm{NaHCO}_{3}$ can be less than 1 euro/kg and the $\mathrm{CaO}$ available in any building store comes up to only $0.2 \mathrm{euro} / \mathrm{kg}$. The neutralization process using FA showed a neutralization efficiency of $0.95 \mathrm{~kg}$ calculated as pure $\mathrm{H}_{2} \mathrm{SO}_{4}$ per $1 \mathrm{~kg}$ of $\mathrm{MgO}-\mathrm{TiO}_{2}$. It is easy to calculate that, for example, the use of $\mathrm{CaO}$ would allow the neutralization of $1.75 \mathrm{~kg} \mathrm{H}_{2} \mathrm{SO}_{4}$ (and with a product fully neutralized to $\mathrm{CaSO}_{4}$ ). Another solution that would be much cheaper than nanoactive oxide neutralizers would be the use of $\mathrm{NaHCO}_{3}, \mathrm{Na}_{2} \mathrm{CO}_{3}, \mathrm{NaOH}$ or even decahydrate of $\mathrm{Na}_{2} \mathrm{~B}_{4} \mathrm{O}_{7}$.

Experiments show that without mixing and with big excess of $\mathrm{H}_{2} \mathrm{SO}_{4}$ (mass ratio neutralizer: $\mathrm{H}_{2} \mathrm{SO}_{4} 1: 10$ ), the energy effect of the neutralization process with nanocrystalline $\mathrm{Mgo}^{-} \mathrm{TiO}_{2}$ provides a slightly better guarantee of safety at the time of its adding than the solutions used so far (Figure 9, Table 3).

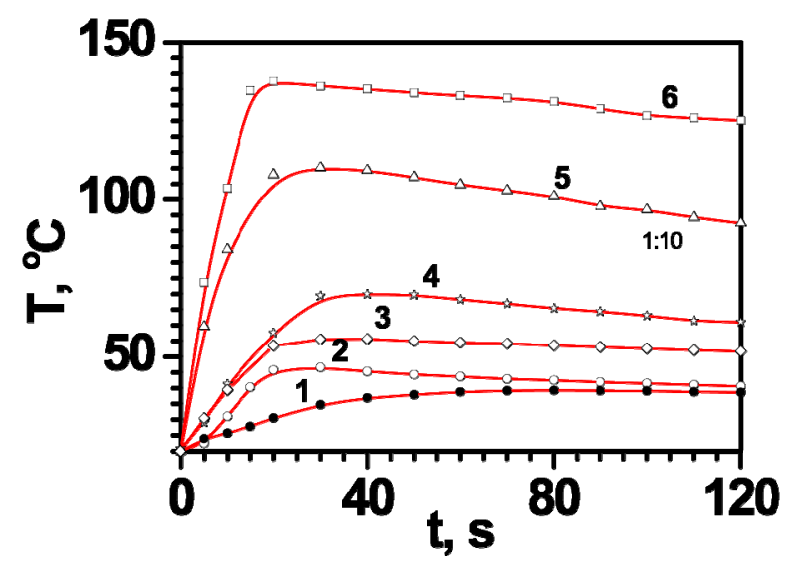

Figure 9. Temperature dependence as function of time in the process of neutralization $98 \% \mathrm{H}_{2} \mathrm{SO}_{4}$ through (1) FA (MgO-TiO丶 $)$, (2) $\mathrm{NaHCO}_{3},(3) \mathrm{Na}_{2} \mathrm{CO}_{3}$, (4) $\mathrm{CaO}$, (5) $\mathrm{Ca}(\mathrm{OH})_{2},(6) \mathrm{NaOH}$. Mass ratio neutralizer: $\mathrm{H}_{2} \mathrm{SO}_{4} 1: 10$. Method of adding the neutralizer: loose pouring (without mixing). $\mathrm{T}_{0}=20^{\circ} \mathrm{C}$.

Table 3. Temperature increase and maximum temperature change over time for neutralization processes $98 \% \mathrm{H}_{2} \mathrm{SO}_{4}$ through FA, $\mathrm{NaHCO}_{3}, \mathrm{Na}_{2} \mathrm{CO}_{3}, \mathrm{Ca}(\mathrm{OH})_{2}, \mathrm{NaOH}, \mathrm{CaO}$. Mass ratio neutralizer: $\mathrm{H}_{2} \mathrm{SO}_{4}$ 1:10. Method of adding the neutralizer: loose pouring (without mixing). $\mathrm{T}_{0}=20^{\circ} \mathrm{C}$.

\begin{tabular}{ccc}
\hline Neutralizer & $\boldsymbol{\Delta} \mathbf{T},{ }^{\circ} \mathbf{C}$ & $\left(\boldsymbol{\Delta} \mathbf{T} \boldsymbol{\Delta} \mathbf{t}^{-\mathbf{1}}\right)^{\circ} \mathbf{C ~ s}^{\mathbf{- 1}}$ \\
\hline${\mathrm{MgO}-\mathrm{TiO}_{2}(\mathrm{FA})}$ & 19.3 & 0.8 \\
\hline $\mathrm{NaHCO}_{3}$ & 26.6 & 1.9 \\
\hline $\mathrm{Na}_{2} \mathrm{CO}_{3}$ & 35.6 & 2.1 \\
\hline $\mathrm{Ca}(\mathrm{OH})_{2}$ & 90.2 & 7.9 \\
\hline $\mathrm{NaOH}$ & 117.6 & 10.7 \\
\hline $\mathrm{CaO}$ & 49.9 & 2.5 \\
\hline
\end{tabular}

While the temperature increase (at a weight ratio of neutralizer: $\mathrm{H}_{2} \mathrm{SO}_{4}(1: 10)$ for solid $\mathrm{Ca}(\mathrm{OH})_{2}$ and $\mathrm{NaOH}$ was significantly greater causing boiling and spreading of the pool $\left(\Delta \mathrm{T}_{\mathrm{Ca}(\mathrm{OH}) 2}=90.2^{\circ} \mathrm{C}\right.$, $\Delta \mathrm{T}_{\mathrm{NaOH}}$ solid $\left.=117.6^{\circ} \mathrm{C}\right)$, small differences were observed for $\mathrm{NaHCO}_{3}$ neutralization $\left(\Delta \mathrm{T}_{\mathrm{NaHCO}}\right.$ $\left.=26.6{ }^{\circ} \mathrm{C}\right)$ as compared to $\mathrm{FA}\left(\Delta \mathrm{T}_{\mathrm{MgO}-\mathrm{TiO} 2}=19.3{ }^{\circ} \mathrm{C}\right)$. In the conditions of rescue and firefighting operations, the rate of the sodium bicarbonate neutralization process is sufficiently fast and does not require acceleration by mixing. On the other hand, nanocrystalline $\mathrm{MgO}-\mathrm{TiO}_{2}$ floats on the surface of the pool and reacts slowly, so mixing is necessary to speed up the reaction. The mixing process causes a two-fold increase in temperature $\left(\Delta \mathrm{TMgO}-\mathrm{TiO}_{2}=46.0^{\circ} \mathrm{C}\right)$ as compared to the reaction with free 
pouring without mixing. Studies have shown that in the case of neutralization including mixing in the mass ratio of $\mathrm{MgO}-\mathrm{TiO}_{2}$ to $\mathrm{H}_{2} \mathrm{SO}_{4}$ of $1: 2$, the temperature increase $\Delta \mathrm{T}$ can be as high as $170{ }^{\circ} \mathrm{C}$, and consequently poses a more intense risk of burns due to careless operation of the rescuer than it is the case for $\mathrm{NaHCO}_{3}$ at the same ratio $\left(\Delta \mathrm{T}_{\mathrm{NaHCO} 3}=74.8^{\circ} \mathrm{C}\right)$. An additional advantage of sodium bicarbonate (as well as other carbonates) is the ability of controlling the neutralization process by easily observing the evolution of $\mathrm{CO}_{2}$. This is not possible with nanocrystalline oxide specimens, and the determination of the end of backwater neutralization process requires an indicator (unless it is first solidified). This is of particular importance for rescuers working in a zone with a significantly restricted visibility splay wearing gas-tight clothing.

The neutralization processes executed by rescuers on the incident scene require assuring special safety conditions. Depending on the type of acid being neutralized, rescue actions require protection in the form of anti-splash clothing or chemically resistant gas-tight clothing. This makes work conditions highly uncomfortable. The execution of additional activities (such as for example mixing) causes increased amounts of vapor being released and fogging of the visor. On the other hand, intense water vaporization during excessive temperature increase during neutralization may also cause, apart from thermal burns, total blocking of the rescuer's visibility splay.

\section{Conclusions}

This article analyses the scope of practical application of metal nanooxides with view to needs of the rescuers during uncontrolled releases of hazardous substances. In the testing, use was made of commercially available $\mathrm{MgO}-\mathrm{TiO}_{2}$ sold under the trade name of FastAct (FA). Its proprieties were compared to selected sorbents that are commonly used by rescuers during actions, generally marked as CDE (granulated sorbent based on calcined diatomaceous earth), PC (polyacrylamide copolymer), EP (expanded perlite).

It can be seen clearly that the nanocrystalline $\mathrm{MgO}^{-\mathrm{TiO}_{2}}$ specimen (FA) does not exhibit higher maximal mass sorptivity $S_{\mathrm{w}}$ or maximal volume sorptivity $S_{\mathrm{v}}$ in relation to sorbents used so far during rescue operations. Much better $S_{w}$ results were obtained for expanded perlite (EP) and water activated polyacrylamide copolymer (PC). As compared to $\mathrm{MgO}^{-} \mathrm{TiO}_{2}$, the $\mathrm{S}_{\mathrm{v}}$ parameter was found to be better not only for water-activated PC but also for calcinated diatomite earth sorbent (CDE). Considering also the significantly higher prices of nanooxides ( $\mathrm{min} .50 \mathrm{euro} / \mathrm{kg}$ ), their use as sorbents of hydrocarbon substances seems to be highly unprofitable for the time being. The majority of sorbents currently used by fire services have a price much lower than 5 euro $/ \mathrm{kg}$.

Furthermore, despite a well-developed surface structure FA does not assure protection from evaporation of sorbate from its surface. Measurements with n-heptane and ethanol have shown that even at a mass ratio sorbent:sorbate that is far from maximal sorptivity, the weight loss of sorbate from FA is similar in magnitude and even greater than the weight loss recorded for evaporation from the surface of pure sorbates (n-heptane and ethanol). This confirms the presumption about the decisive role of physical sorption on $\mathrm{MgO}^{-\mathrm{TiO}_{2}}$ surface in the case of hydrocarbons and monohydric alcohols. However, increased evaporation could also result from the very large specific surface area. The increase of a fire hazard was also confirmed by comparative studies of ignition temperature of pure $p$-xylene and in configuration p-xylene:FA and p-xylene:CDE. At a mass ratio of 1:2 the vapor ignition temperature was found to decrease both in the case of $\mathrm{p}$-xylene absorbed by CDE and FA.

This proves that this neutralizer is not appropriate for trapping hydrocarbon vapors and alcohols from the air, which constitute the biggest group of chemical fire hazards in industry and in transport.

Studies have pointed to a considerable susceptibility of nanooxides to ageing, which is of particular importance for the storage of those compounds. As a result of the large proper surface of $\mathrm{MgO}-\mathrm{TiO}_{2}$, the rate of water absorption is 12-fold bigger than for the hygroscopic $\mathrm{CaO}$. On the other hand, hydrophobized $\mathrm{ABC}$ powder (Extinguishing powder dedicated for $\mathrm{ABC}$ group fires (solids, liquids, gases)) with a monoammonium phosphate content of $90 \%$ absorbs water 37 times slower than FA. 
The energetic effect of the neutralization process by FA during unconstrained pouring does not assure a much better safety of rescue operations than, for example, in the case of $\mathrm{NaHCO}_{3}$. To allow the process to take place relatively quickly mixing is essential, as fine and hydrophobised nanocrystallite remains at the acid surface, reacting slowly.

In addition the mixing process causes a two-fold increase in temperature $\left(\Delta \mathrm{TMgO}-\mathrm{TiO}_{2}=46.0^{\circ} \mathrm{C}\right)$ than was the case for the reaction with free pouring without mixing. Studies have shown that in the case of neutralization including mixing in the mass ratio of $\mathrm{MgO}^{-} \mathrm{TiO}_{2}$ to $\mathrm{H}_{2} \mathrm{SO}_{4}$ of 1:2, the temperature increase $\Delta \mathrm{T}$ can be as high as $170{ }^{\circ} \mathrm{C}$, consequently posing a much more material risk of burns due to careless operation of the rescuer than is the case for $\mathrm{NaHCO}_{3}$ at the same ratio $\left(\Delta \mathrm{T}_{\mathrm{NaHCO} 3}=74.8^{\circ} \mathrm{C}\right)$.

Similar to sorption, the neutralization processes of typical acids involving nanoactive oxide neutralizers are very costly as compared to commercially available neutralizers. For example the price of $\mathrm{CaO}$ available in any building materials store is only $0.2 \mathrm{Euro} / \mathrm{kg}$ and technical $\mathrm{NaHCO}_{3}$ costs less than $1 \mathrm{euro} / \mathrm{kg}$. By contrast with $\mathrm{MgO}-\mathrm{TiO}_{2}$, an additional advantage of sodium bicarbonate (as well as other carbonates) is the ability to control the neutralization process by easily observing the evolution of $\mathrm{CO}_{2}$. This is of great importance for rescuers working in a zone having a significantly restricted visibility splay in gas-tight clothing.

Author Contributions: Conceptualization, T.W., M.M.-Ł., A.W.; Data curation, T.W., M.M.-Ł.; Formal analysis, T.W., M.M.-E., A.W.; Investigation, T.W. and M.M.--.; Methodology, M.M.-Ł. and T.W.; Supervision, T.W., M.M.-Ł.; Validation, T.W., M.M.-Ł.; Visualization, T.W. M.M.-Ł, A.W.; Writing-original draft, T.W., M.M.-Ł.; Writing-review \& editing, T.W. M.M.-, A.W. All authors have read and agreed to the published version of the manuscript.

Funding: The research was carried out as part of the DOB-BIO6/06/11/2014 project "Mobile turbine rescue and firefighting system" financed by The National Centre for Research and Development in Poland (NCBiR).

Conflicts of Interest: The authors declare no conflicts of interests.

\section{References}

1. Center for Chemical Process Safety of the American Institute of Chemical Engineers. Guidelines for Use of Vapour Cloud Dispersion Models; Wiley-AIChE: New York, NY, USA, 1996.

2. Wẹsierski, T.; Gałązkowski, R.; Zboina, J. Determining the danger zone during the chemical rescue action. Przem. Chem. 2012, 91, 582-584.

3. NanoScale Corporation. Chemical Hazard Containment and Neutralization System, FAST-ACT Technical Report; FAP03 v. 64/11; NanoScale Corporation: Research Park Drive, Manhattan, KS, USA, 2011.

4. Wagner, G.W.; Sorrick, D.C.; Procell, L.R.; Brickhouse, M.D. Decontamination of VX, GD and HD on a surface using modified vaporised hydrogen peroxide. Langmuir 2007, 23, 1178-1186. [CrossRef]

5. Wagner, G.W.; Procell, L.R.; Yang, Y.C.; Bunton, C.A. Molybdate/peroxide oxidation of mustard in microemulsions. Langmuir 2001, 17, 4809-4811. [CrossRef]

6. Dong, J.; Lv, H.; Sun, X.; Wang, Y.; Ni, Y.; Zou, B.; Zhang, N.; Yin, A.; Chi, Y.; Hu, C. A Versatile Self-Detoxifying Material Based on Immobilized Polyoxoniobate for Decontamination of Chemical Warfare Agent Simulants. Chemistry 2018, 24, 19208-19215. [CrossRef]

7. Singh, B.; Prasad, G.K.; Pandey, K.S.; Danikhel, R.K.; Vijayaraghavan, R. Decontamination of Chemical Warfare Agents. Def. Sci. J. 2010, 60, 428-441. [CrossRef]

8. Zhang, M.; Chen, X.; Zhou, H.; Murugananthan, M.; Zhang, Y. Degradation of p-nitrophenol by heat and metal ions co-activated persulfate. Chem. Eng. J. 2015, 264, 39-47. [CrossRef]

9. Harmata, W.; Kłosowicz, S.J.; Chałupczak, M.; Pẹpczyńska, M.; Pirszel, J. Mobile system for decontamination barrier materials and equipment contaminated with sulfur musztard. Przem. Chem. 2014, 93, 468-471.

10. Waysbort, D.; McGarvey, D.J.; Creasy, W.R.; Morrissey, K.M.; Hendrickson, D.M.; Dupont Durst, H. A decontamination system for chemical weapons agents using a liquid solution on a solid sorbent. J. Hazard. Mater. 2009, 161, 1114-1121. [CrossRef]

11. Gordon, R.K.; Clarkson, E.D. Rapid Decontamination of Chemical Warfare Agents. In Handbook of Toxicology of Chemical Warfare Agents; Ramesh, C.G., Ed.; Academic Press: Cambridge, MA, USA, 2009.

12. Sadeghi, M.; Yekta, S.; Ghaedi, H. Decontamination of chemical warfare sulfur mustard agent stimulant by ZnO nanoparticles. Int. Nano Lett. 2016, 6, 161-171. [CrossRef] 
13. Prasad, G.K.; Mahato, T.H.; Pandey, P.; Singh, B.; Suryanarayana, M.V.S.; Saxena, A.; Shekhar, K. Reactive sorbent based on manganese oxide nanotubes and nanosheets for the decontamination of 2-chloroethyl ethyl sulphide. Microporous Mesoporous Mater. 2007, 106, 256-261. [CrossRef]

14. Stark, J.V.; Park, D.G.; Lagadic, I.; Klabunde, K.J. Nanoscale metal oxide particle/clusters as chemical reagents, Unique surface chemistry on magnesium oxide as shown by enhanced adsorption of acid gases(sulfur oxide and carbon dioxide) and pressure dependenc. Chem. Mater. 1996, 8, 1904-1912. [CrossRef]

15. Dadvar, S.; Tavanai, H.; Morshed, M.; Ghiaci, M. The removal of 2-chloroethyl ethyl sulfide using activated carbon nanofibers embedded with $\mathrm{MgO}$ and $\mathrm{Al}_{2} \mathrm{O}_{3}$ nanoparticles. J. Chem. Eng. Data 2012, 57, 1456-1462. [CrossRef]

16. Sharma, N.; Kakkar, R. Adsorption of sarin on MgO nanotubes: Role of doped and defect sites. J. Comput. Sci. 2015, 10, 225-236. [CrossRef]

17. Michalkova, A.; Ilchenko, M.; Gorb, L.; Leszczynski, J. Theoretical study of the adsorption and decomposition of sarin on magnesium oxide. J. Phys. Chem. B 2004, 108, 5294-5303. [CrossRef]

18. Wang, X.; Kim, S.; Buda, C.; Neurock, M.; Koper, O.B.; Yates, J.T. Direct Spectroscopic Observation of the Role of Humidity in Surface Diffusion through an Ionic Adsorbent Powder. The Behavior of Adsorbed Pyridine on Nanocrystalline MgO. J. Phys. Chem. C 2009, 113, 2228-2234. [CrossRef]

19. Bartram, P.W.; Wagner, G.W. Decontamination of Chemical Warfare Agents Using Activated Aluminium Oxide. U.S. Patent No. 5689038, 1997.

20. Mawhinney, D.B.; Rossin, J.A.; Gehart, K.; Yates, J.T. Adsorption and reaction of 2-Chloroethylethyl Sulfide with $\mathrm{Al}_{2} \mathrm{O}_{3}$ surfaces. Langmuir 1999, 15, 4789-4795. [CrossRef]

21. Verma, M.; Gupta, V.K.; Dave, V.; Chandra, R.; Prasad, G.K. Synthesis of sputter deposited CuO nanoparticles and their use for decontamination of 2-chloroethyl ethyl sulfide (CEES). J. Colloid Interface Sci. 2015, 438, 102-109. [CrossRef]

22. Mahato, T.H.; Singh, B.; Srivastava, A.K.; Prasad, G.K.; Srivastava, A.R.; Ganesan, K.; Vijayaraghavan, R. Effect of calcinations temperature of $\mathrm{CuO}$ nanoparticle on the kinetics of decontamination and decontamination products of sulphur mustard. J. Hazard. Mater. 2011, 192, 1890-1895. [CrossRef]

23. Wagner, G.W.; Yang, Y.-C. Rapid Nucleophilic/Oxidative Decontamination of Chemical Warfare. Ind. Eng. Chem. Res. 2002, 41, 1925-1928. [CrossRef]

24. Prasad, G.K.; Mahato, T.H.; Singh, B.; Ganesan, K.; Srivastava, A.R.; Kaushik, M.P.; Vijayraghavan, R. Decontamination of Sulphur Mustard and Sarin on titanium nanotubes. AlChE J. 2008, 54, $2957-2963$. [CrossRef]

25. Mahato, T.H.; Prasad, G.K.; Singh, B.; Acharya, J.; Srivastava, A.R.; Vijayaraghavan, R. Nanocrystalline zinc oxide for the decontamination of sarin. J. Hazard. Mater. 2009, 165, 928-932. [CrossRef]

26. Mahato, T.H.; Prasad, G.K.; Singh, B.; Srivastava, A.R.; Ganesan, K.; Acharya, J.; Vijayaraghavan, R. Reactions of sulphur mustard and sarin on $\mathrm{V}_{1.02} \mathrm{O}_{2.98}$ nanotubes. J. Hazard. Mater. 2009, 166, 1545-1549. [CrossRef]

27. Vu, A.T.; Jiang, S.; Ho, K.; Lee, J.; Lee, C.H. Mesoporous magnesium oxide and its composites: Preparation, characterization, and removal of 2-chloroethyl ethyl sulfide. Chem. Eng. J. 2015, 269, 82-93. [CrossRef]

28. Nazari, B.; Jaafari, M. A new method of synthesis of $\mathrm{MgO}$ nanoparticles for the destructive adsorption of organo-phosphorus compounds. Die. J. Nanomater. Biostruct. 2010, 5, 909-917.

29. Volodin, A.M.; Bedilo, A.F.; Heroux, D.S.; Zaikovskii, V.I.; Mishakov, I.V.; Chesnokov, V.V.; Klabunde, K.J. Nanoscale oxides as destructive sorbents for halogenated hydrocarbons. Surf. Chem. Biomem. Envirom. Sci. 2006, 228, 403-412.

30. Khaleel, A.; Kapoor, P.N.; Klabunde, K.J. Nanocrystalline metal oxides as new adsorbents for air purification. Nanostruct. Mater. 1999, 11, 459-468. [CrossRef]

31. Lucas, E.M.; Klabunde, K.J. Nanocrystals as destructive adsorbants for mimcs of chemical warfare agents. Nanostruct. Mater. 1999, 12, 179-182. [CrossRef]

32. Cui, Z.; Zhang, J.; Xue, Y. Size-Dependent Thermodynamitcs and Kinetics of Adsorption on Nanoparticles: A Theoretical and Experimental Study. Langmuir 2018, 34, 3197-3206. [CrossRef]

33. Bhadra, J.; Abdulkareem, A.; Al-Thani, N. Nanotechnology in decontamination. In Composite Nanoadsorbents. Micro and Nano Technologies; Kyzas, G.Z., Mitropoulos, A.C., Eds.; ELSEVIER: Oxford, UK, 2019; pp. $119-137$.

34. Li, Y.X.; Klabunde, K.J. Nanoscale Metal-Oxide Particles as Chemical Reagents-Destructive Adsorption of A Chemical-Agent Simulant, Dimethyl Methylphosphonate, on Heat-Treated Magnesium-Oxide. Langmuir 1991, 7, 1388-1393. [CrossRef] 
35. Wagner, G.W.; Bartram, P.W.; Koper, O.; Klabunde, K.J. Reactions of VX, GD and HD with nano-size MgO. J. Phys. Chem. B 1999, 103, 3225-3228. [CrossRef]

36. Wagner, G.W.; Koper, O.; Lucas, E.; Decker, S.; Klabunde, K.J. Reactions of VX, GD and HD with nanosize CaO: Autocatalytic dehydrohalogenation of HD. J. Phys. Chem. B 2000, 104, 5118-5123. [CrossRef]

37. Decker, S.; Klabunde, K.J. Enhancing effect of Fe2O3 on the ability of nanocrystalline calcium oxide to adsorb $\mathrm{SO}_{2}$. J. Am. Chem. Soc. 1996, 118, 12465-12466. [CrossRef]

38. Narske, R.M.; Klabunde, K.J.; Fultz, S. Solvent effects on the heterogeneous adsorption and reactions of (2-chloroethyl) ethyl sulfide on nanocrystalline magnesium oxide. Langmuir 2002, 18, 4819-4825. [CrossRef]

39. Klabunde, K.J.; Medine, G.; Bedilo, A.F.; Stoimenow, P.; Heroux, D. Nanocrystalline metal oxides: A new family of mesoporous inorganic materials useful for destructive adsorption of environmental toxins. ACS Symp. Ser. 2005, 890, 272-276.

40. Bedilo, A.F.; Sigel, M.J.; Koper, O.B.; Melgunov, M.S.; Klabunde, K.J. Synthesis of carbon-coated MgO nanoparticles. J. Mater. Chem. 2002, 12, 3599-3604. [CrossRef]

41. Klabunde, K.J. Nanoscale Materials in Chemistry; John Wiley \& Sonc Inc.: New York, NY, USA, 2001.

42. Finocchi, F.; Goniakowski, J. Interaction of a water molecule with oxygen vacancy on the $\mathrm{MgO}(100)$ surface. Phys. Rev. B 2001, 64, 125426-125433. [CrossRef]

43. Prasad, G.K.; Ramacharyulu, P.V.R.K.; Batra, K.; Singh, B.; Srivastava, A.R. Decontamination of Yperite using mesoporous mixed metal oxide nanocrystals. J. Hazard. Mater. 2010, 183, 847-852. [CrossRef]

44. Prasada, G.K.; Singha, B.; Ganesana, K.; Batrab, A.; Kumeriab, T.; Gutcha, P.K.; Vijayaraghavana, R. Modified titania nanotubes for decontamination of sulphur mustard. J. Hazard. Mater. 2009, 167, 1192-1197. [CrossRef]

45. Koper, O.B.; Rajagopalan, S.; Winecki, S.; Klabunde, K.J. Nanoparticle Metal Oxides for Chlorocarbon and Organophosphonate Remediation. In Environmental Applications of Nanomaterials: Synthesis, Sorbents and Sensors, 2nd ed.; Fryxell, G.E., Cao, G., Eds.; World Scientific Publishing Co. Pte. Ltd.: Singapore, 2007.

46. Branda, M.M.; Rodríguez, A.H.; Belelli, P.G.; Castellani, N.J. Ethanol adsorption on MgO surface with and without defects from a theoretical point of view. Surf. Sci. 2009, 603, 1093-1098. [CrossRef]

47. Bandura, L.; Woszuk, A.; Kołodyńska, D.; Franus, W. Application of Mineral sorbents for Removal of Petroleum Substances: A Review. Minerals 2017, 7, 37. [CrossRef]

48. Tic, W. Characteristics of adsorbents used to remove petroleum contaminants from soil and wastewater. Przemysl Chemiczny 2015, 1, 79-84. [CrossRef] 